\title{
Familial occurrence of congenital incomplete prepyloric mucosal diaphragm
}

\author{
D B Gahukamble
}

\begin{abstract}
Incomplete prepyloric mucosal diaphragm (IPMD) is an uncommon congenital anomaly that leads to gastric outlet obstruction in infancy and childhood. This report describes the occurrence of IPMD in six children in a closely knit tribal family from a geographically isolated desert town with a small population in the Sahara. Their records showed similarities of clinical, radiological, operative, and histopathological features. These features, as well as its occurrence in brothers, sisters, and cousins, suggest that this unusual anomaly is transmitted as an autosomal recessive trait. (F Med Genet 1998;35:1040-1042)
\end{abstract}

Keywords: gastric outlet obstruction; prepyloric web; prepyloric membrane

Prepyloric mucosal diaphragm is now a well established clinical entity and is situated 1-2 cm proximal to the pylorus. ${ }^{1}$ It is an uncommon cause of gastric outlet obstruction in infancy and childhood. During the last few decades case reports have been published, but few series. ${ }^{2-4}$ Despite reports of a fairly large number of patients with this anomaly, its occurrence in sibs or cousins has not been recorded and the cause is not known. Genetic influences have been detected in patients who have a complete atretic lesion at this site, ${ }^{5}$ but this has not been documented or suspected in patients with an incomplete septum. This report of its multiple occurrence in a close family unit supports the hypothesis that this anomaly is genetically inherited.

\section{Case reports}

In September 1996, a 13 month old female infant, born to a non-consanguineous couple, was admitted because of intermittent nonbilious vomiting since the age of 6 months. The mother also noticed distension and rolling movements over the upper abdomen. There
Heineke-Miculicz pyloroplasty was performed. Histological examination of the excised diaphragm showed a thin septum lined on both sides by apparently normal looking gastric mucosa with no muscular layer in the core (fig 2).

The patient's mother volunteered that there had been similar instances in the first cousins of her daughter who had also been treated in our unit previously. She even described the site and direction of the scars in two of them This prompted us to review the records of these patients and to obtain further family data.

After consultation with the proband's mother it was possible to obtain details of the entire family. The records of the children who had been operated upon were retrieved and reviewed. Data obtained included age at presentation and clinical and operative findings (table 1). Histological slides of all the patients were reviewed. History of drug consumption during pregnancy and present status of the children was ascertained. From the available data, a pedigree (fig 3) was constructed. Karyotyping of the proband's parents was performed.

The entire tribal family unit comes from a small, isolated, oasis town in the Sahara desert separated from populated areas of the country by hundreds of kilometres.

In branch A, two sisters (III.2 and III.5) were operated on for IPMD. There were three deaths. One boy (III.4) died in infancy from an

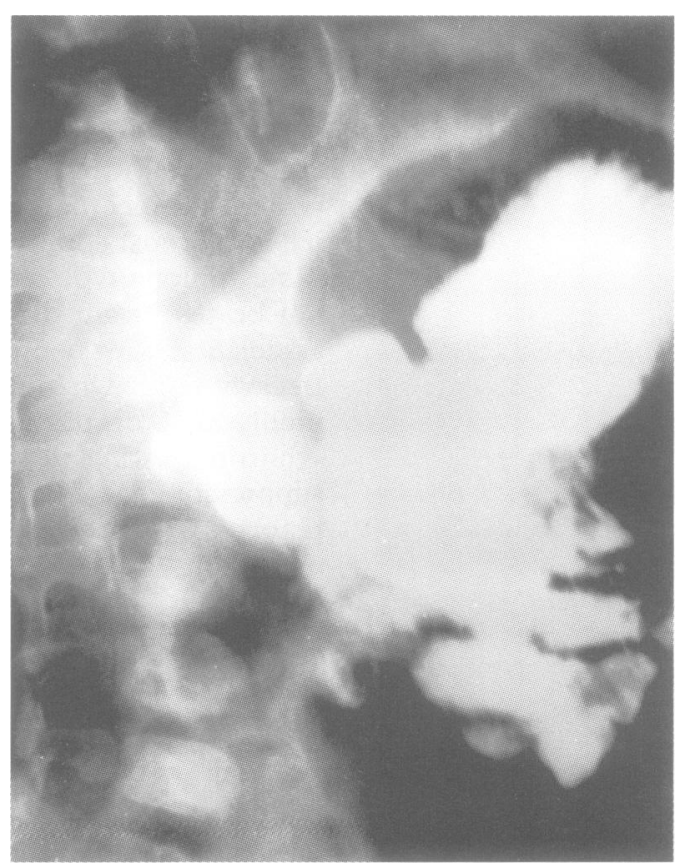

Figure 1 Barium study showing thin filling defect in the prepyloric region and a dilated stomach. \author{
was no history of failure to thrive and the \\ infant was born normally at term. The mother \\ had polyhydramnios during the pregnancy. \\ Clinical examination showed visible gastric \\ peristalsis. Contrast studies showed a dilated \\ stomach and slow passage of barium into the \\ duodenum. There was a thin filling defect in \\ the prepyloric region (fig 1). Barium was \\ retained in the stomach for more than four \\ hours. At laparotomy, a vertical groove over \\ the prepyloric region was clearly noticeable. A \\ longitudinal incision was made, a thin mem- \\ branous mucosal diaphragm was excised, and \\ Received 7 October 1997 \\ Revised version accepted fo \\ publication 22 April 1998 \\ Paediatric Surgery, \\ Libya \\ Correspondence to: \\ Dr Gahukamble, Post Box \\ 7199, Birkha, Benghazi
}




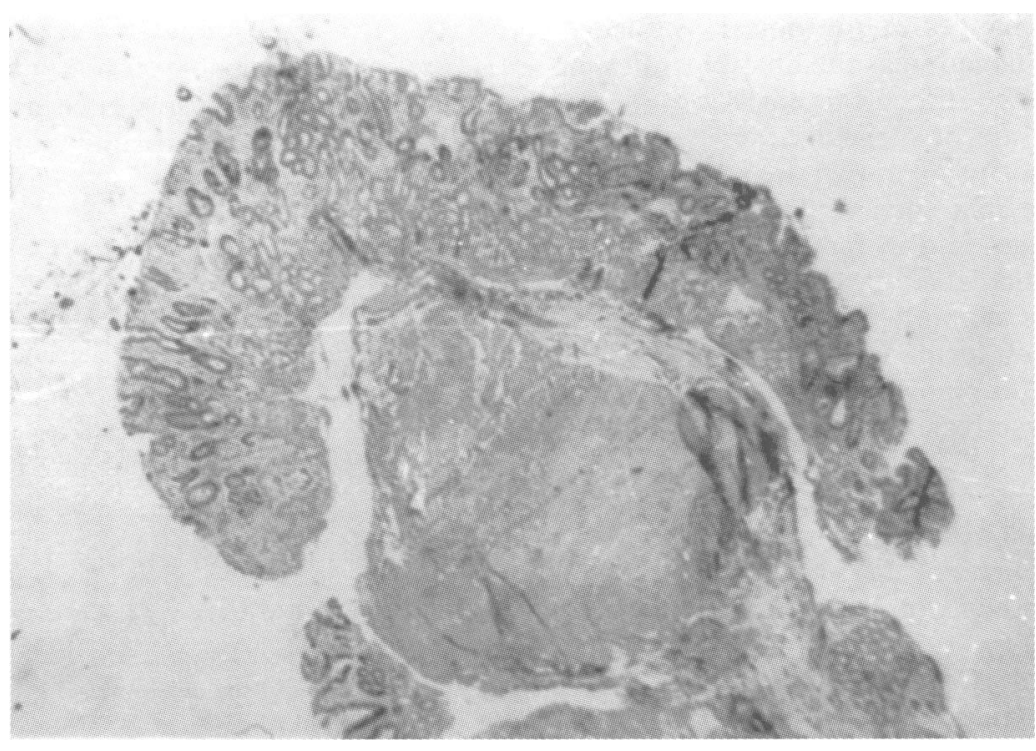

Figure 2 Histopathological appearance of excised diaphragm showing gastric mucosa with no muscle layers (HEE).
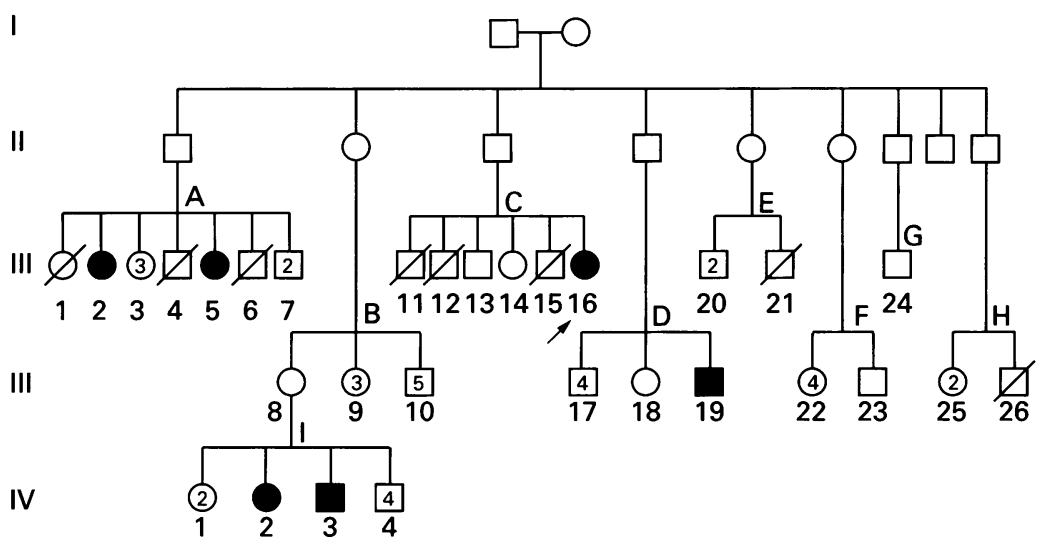

\section{$\square \varnothing$ Deaths $\square$ Affected $/$ Proband}

Figure 3 Family pedigree.

insect bite. Another male child (III.6) and a female neonate (III.1) died of unknown causes. The other children were healthy.

In branch $\mathrm{B}$, all the sibs were healthy. Two children of the oldest girl (III.8), a girl (IV.2) and a boy (IV.3), were operated on for IPMD in our unit in early infancy.

In the proband's branch (C), the parents have two other healthy children (III.13 and III.14) but there were three deaths. One male (III.11) died after premature birth at 7 months. Another male (III.12) died on the 25th day as a consequence of jaundice and vomiting. The third male (III.15) died after repeated vomiting on the 36th day. In both the cause of death was unknown.
All the sibs in branch D were healthy except the youngest boy (III.19) who had surgery for IPMD.

In branch $\mathrm{E}$, there was one death (III.21) of unknown cause and two healthy children. In branch $F$, all sibs were healthy. There was one neonatal death (III.26) in branch H. This was a large baby who had abdominal distension. Thus, six children from a large extended family of common ancestry were treated for IPMD, with occurrence in sibs and cousins. The histopathological appearances of the excised membranes were also strikingly similar. All the patients have done well. A notable feature in the families was the absence of consumption of drugs by the mothers of these affected children in pregnancy. Karyotyping of the proband's parents was normal.

\section{Discussion}

All six patients including two pairs of sibs were members of a close family unit from a geographically isolated town. The clinical, radiological, and operative findings and the histopathological appearances of the excised diaphragms were similar. Clinically, there were no symptoms during early infancy in any of them as fluid could pass easily through the aperture in the diaphragm. However, later, when thickened feeds and solids were started, this became increasingly difficult leading to symptoms of gastric outlet obstruction. The occurrence of this lesion in infancy, the lack of signs of inflammation such as inflammatory cells and fibrosis, and the uniformity of the histological appearance undoubtedly points to the fact that this is a congenital lesion. The lack of muscular elements in the wall of the septum is indicative of the fact that this lesion is derived from the endodermal layer.

In previous reports, a search was made to detect additional congenital malformations in patients with IPMD. Apart from one report, ${ }^{6}$ others ${ }^{12}$ have documented various anomalies in their patients. Our records did not show any gross associated anomalies in our patients but no detailed investigations were done to detect any asymptomatic major or minor malformations in other systems. There were seven infant deaths among the sibs and cousins of the patients presented here. Although the causes of death remain speculative, they could have been the result of congenital malformations or consequences thereof.

The cause of IPMD has not been fully elucidated. Numerous proposals have been made to explain the occurrence of this rare anomaly. The generally agreed belief that intrauterine vascular accidents cause ischaemic necrosis

Table 1 Clinical data of the patients

\begin{tabular}{|c|c|c|c|c|c|c|}
\hline Patients & $\begin{array}{l}\text { Age at } \\
\text { presentation }\end{array}$ & $\begin{array}{l}\text { Year of } \\
\text { presentation }\end{array}$ & Sex & Clinical presentation & Operative findings & $\begin{array}{l}\text { Age and condition at } \\
\text { follow up }\end{array}$ \\
\hline III.2 & $1 \mathrm{y}$ & 1983 & $\mathbf{F}$ & Non-bilious vomiting and visible peristalsis & Incomplete prepyloric mucosal diaphragm & $15 \mathrm{y}$, alive and well \\
\hline IV.I2 & $2 \mathrm{y}$ & 1984 & $\mathrm{~F}$ & Non-bilious vomiting and visible peristalsis & Incomplete prepyloric mucosal diaphragm & $14 \mathrm{y}$, alive and well \\
\hline IV.I3 & $2 y$ & 1993 & M & Non-bilious vomiting and visible peristalsis & Incomplete prepyloric mucosal diaphragm & $6 \mathrm{y}$, alive and well \\
\hline III. 5 & $2 \mathrm{y}$ & 1994 & $\mathrm{~F}$ & Non-bilious vomiting and visible peristalsis & Incomplete prepyloric mucosal diaphragm & $4 \mathrm{y}$, alive and well \\
\hline III. 19 & $7 \mathrm{mth}$ & 1995 & M & Non-bilious vomiting and visible peristalsis & Incomplete prepyloric mucosal diaphragm & $1.5 \mathrm{y}$, alive and well \\
\hline III. 16 & $13 \mathrm{mth}$ & 1996 & $\mathrm{~F}$ & Non-bilious vomiting and visible peristalsis & Incomplete prepyloric mucosal diaphragm & $16 \mathrm{mth}$, alive and well \\
\hline
\end{tabular}

III. 2 and III. 5 are sisters, IV.I2 and IV.I3 are sibs. 
and subsequent atretic changes in the bowel segment is unlikely at this location as the blood supply is abundant. It is also difficult to envisage the possibility of failure of recanalisation (Tandler) of fetal bowel occlusion at this site as there is no firm evidence that such occlusion ever occurs in the stomach ${ }^{6}$ and in fact starts below it. ${ }^{7}$ Gray and Skandalakis ${ }^{8}$ have postulated that redundancy and slipping of epithelial lining may initiate the formation of an incomplete diaphragm. Although this appears to be a possible and attractive explanation, it still remains speculative and definite confirmatory evidence is not available to date. The similarities of the clinicopathological features in all the patients and its occurrence in sibs and cousins point, in the absence of teratogenic factors, to a genetic aetiology.

The pedigree of these sibships from an inbred population shows maternal as well as paternal transmission in two successive generations. Its occurrence in both sexes, sibs, and cousins indicates that autosomal recessive inheritance is the most probable mode of transmission, with other mechanisms such as multifactorial inheritance being possible but less likely.

1 Bell MJ, Ternberg JL, McAlister W, et al. Antral diaphragm - a cause of gastric outlet obstruction for children. $\mathcal{F}$ Pediat 1977;90:196-202.

2 Bell MJ, Ternberg JL, Keating JP, et al. Prepyloric gastric antral web: a puzzling epidemic. $\mathcal{f}$ Pediatr Surg 1978;13: antral we

3 Berr F, Riemueller R, Sauerburch T. Successful endoscopic transection of a partially obstructing diaphragm. Gastroen terology 1985;89:1 147-57.

4 Moore CCM. Congenital gastric outlet obstruction. $f$ Pediatr Surg 1989;24:1241-6.

5 Keramidas DC. Congenital pyloric atresia in siblings. Arch Surg 1974;108:123.

6 Tunnel WP, Smith EI. Antral web in infancy. $\mathcal{F}$ Pediatr Surg 1980;15:152-5.

7 Boyden EA, Cope JG, Bill AH. Anatomy and embryology of congenital intrinsic obstruction of the duodenum. $A m \mathcal{F}$ Surg 1967;114:190-2.

8 Gray S, Skandalakis J. Anomalies of the stomach. In: Gray S, Skandalakis J, eds. Embryology for surgeons. Philadelphia: Saunders, 1972:105-6. 